\title{
Article \\ Research on Regularities of Cyclic Air Motion through a Respirator Filter
}

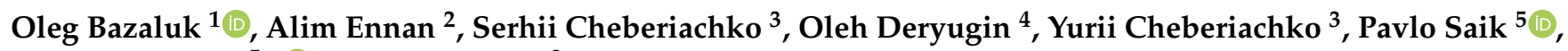 \\ Vasyl Lozynskyi ${ }^{5, *}$ (D) and Ivan Knysh ${ }^{3}$
}

1 Belt and Road Initiative Centre for Chinese-European Studies, Guangdong University of Petrochemical Technology, Maoming 525000, China; bazaluk@ukr.net

2 Institute for Environment and Human Protection, Physical-Chemical Institute for Environment and Human Protection, 65125 Odesa, Ukraine; eksvar@ukr.net

3 Department of Labour Protection and Civil Safety, Dnipro University of Technology, 49005 Dnipro, Ukraine; sicheb@ukr.net (S.C.); cheberiachkoyi@ukr.net (Y.C.); krempromziz@ukr.net (I.K.)

4 Department of Transportation Management, Dnipro University of Technology, 49005 Dnipro, Ukraine; oleg.kot@meta.ua

5 Department of Mining Engineering and Education, Dnipro University of Technology, 49005 Dnipro, Ukraine; saik.nmu@gmail.com

* Correspondence: lvg.nmu@gmail.com

Citation: Bazaluk, O.; Ennan, A.; Cheberiachko, S.; Deryugin, O.; Cheberiachko, Y.; Saik, P.; Lozynskyi, V.; Knysh, I. Research on Regularities of Cyclic Air Motion through a Respirator Filter. Appl. Sci. 2021, 11, 3157. https://doi.org/10.3390/ app11073157

Academic Editor: Elza Bontempi

Received: 19 February 2021

Accepted: 29 March 2021

Published: 1 April 2021

Publisher's Note: MDPI stays neutral with regard to jurisdictional claims in published maps and institutional affiliations.

Copyright: (C) 2021 by the authors Licensee MDPI, Basel, Switzerland. This article is an open access article distributed under the terms and conditions of the Creative Commons Attribution (CC BY) license (https:// creativecommons.org/licenses/by/ $4.0 /)$.

\begin{abstract}
In this paper, a solution to the problem of the change in the pressure drop in a respirator filter during cyclic air motion is suggested since the current theory of filtering is based on steady-flow processes. The theoretical dependence of the pressure drop in the respirator filter on air flow rate is determined, which is represented by the harmonic law, which characterizes the human respiration process during physical work. For the calculation, a filter model was used, which is represented by a system of parallel isolated cylinders with a length equal to the total length of the filter fibres surrounded by porous shells formed by a viscous air flow field, with a size determined by the equal velocities of the radial component of air flow and undisturbed flows. The flow-around process in the proposed model of air flow through the respirator filter is described by the Brinkman equation, which served to establish the total air flow resistance in the proposed system under conditions of velocity proportionality. It consists of two parts: the first characterizes the frictional resistance of the air flow against the surface of the cylinder, which imitates the filter fibre; the second-the inertial part-characterizes the frequency of pulsations of respiratory movements during physical performance. The divergence of the analytical results and experimental studies is no more than $20 \%$, which allows the use of the established dependence to estimate the change in pressure drop in a respirator filter made of filter material "Elephlen" when the user carries out different physical activities. This allows the period of effective protective action of respirators with different cycles of respiration during physical activities to be specified, which is a very serious problem that is not currently regulated in health and safety regulations, and it also allows the prediction of the protective action of filters and respiratory protection in general.
\end{abstract}

Keywords: filter; respirator; cyclic air motion; pressure drop; dust; air drop

\section{Introduction}

The resistance of filters to air flow is one of the most important indicators of filter respirators [1-3]. The protective power time of filters and the user's working capacity depend on its level, which both defines the selection of respiratory protective equipment (RPE) and estimates their protective efficiency [4-7]. In particular, in studies by A.T. Johnson [8], data on the reduction in the working capacity of workers by $25-30 \%$ when using masks with resistance to breath of $80 \mathrm{PA}$ are given. There are also publications on the dependence of the resistance to air flow, passing through filters, on the permeability 
of aerosol particles through them into the space under a mask of a filter respirator [9]. In particular, it is indicated that, due to the dust sediment accumulated on the filters, their protective properties are improved by reducing the pores between the fibres [1]. In addition, a previous study [10] determines the influence of the filter structure (fibre diameter, package density) on resistance to breath and protective properties.

The value of the resistance of the respirator filter to the air flow is calculated based on the pressure drop across the RPE and the air flow rate through it [11,12]. The greatest influence is conditioned by the characteristics of the filtering material from which the filter is made: fibre diameter, fibre packing density, thickness of the filtering layer and the mode of air flow [13].

Currently, theoretical functional connections are known which allow the pressure drop in dust respirators to be defined; these were obtained based on constant air velocity [14-18]. Existing design models of respirator filters do not take into account the cyclicity of the process of a user's breathing when performing production activities-this includes the movement of some volume of air from the atmosphere into their lungs and then back, which requires the use of non-stationary filtering theory, which takes into account the movement of alternating air flow through the filter. Solving such problems is quite an urgent task, as this will allow better determination of the protective parameters of filters, more accurate prediction of the service life of their operation, and a more thorough approach to the creation of new designs of respirators. Therefore, there is a need to develop theoretical studies on the cyclic movement of air flow through the filters of the respirator.

In previous research [19-23], the results of mathematical modelling were presented, in which the filter is represented by the calculation scheme of interconnected channels, where the air motion occurs between two parallel walls. This did not take into account the curvature of the channels, which, in terms of design, is conditioned by the presence of protrusions of individual parts of the fibres of the filtering layer, which results in a decrease in the size of the channels.

The solution to this problem was based on the Euler hydrodynamic equations, taking into account fictitious mass forces of resistance by Zhukovsky. Given that, during respiration, the air movement through the filter can be described by the harmonic law, the following formula [21] was obtained for the pressure drop:

$$
p(y, t)=0.5 \cdot \omega \cdot R_{f} \cdot V_{b} \cdot\left[\sin (\omega t)+e^{-k y} \sin (\omega t-k y)\right],
$$

where $p(y, t)$ is the pressure drop, Pa; $R f$ is the initial resistance value of a clean filter, $(\mathrm{H} \cdot \mathrm{s}) / \mathrm{m}^{3} ; V_{b}$ is the air volume when breathed in and out, $\mathrm{m}^{3} ; \omega$ is the ripple frequency, $1 / \mathrm{s} ; k$ is the parameter which characterizes the permeability of the porous medium, $\left(\mathrm{m}^{-1}\right)$; $y$ is a coordinate, $\mathrm{m}$; $t$ is time, $\mathrm{s}$.

The results of calculating the value of pressure drop for respirator filters by formula (1) show its dependence only on the volume of the inhaled and exhaled air, which fluctuates according to the harmonic law as a material particle, which does not allow the estimation of the influence of the air velocity on the respirator filter resistance under different breathing modes as a result of an increase in the load on the worker when performing the production functions. The model conditions a significant error in the result obtained as compared with the experimental data [19], because it does not consider the change in the filtering velocity, which is related to the area of the filter under consideration, which will have an impact on the initial filter resistance, particularly with increasing load on workers, when structural changes occur in the breathing process: the phase of inhalation decreases in time, while the phase of exhalation, on the contrary, increases, which leads to significant differences between the values of pressure drop in a respirator filter.

The purpose of this research is to solve theoretically the problem of determining the value of the pressure drop on a respirator filter, which is represented by a system of parallel isolated cylinders during the oscillating movement of the air flow with the different modes of physical activity of a worker performing production functions. 
To achieve this purpose, it is necessary to solve the following tasks:

- to determine the flow field in the system of parallel cylinders with cyclic air flow through the respirator filter;

- to determine the new dependence of the change in the pressure drop in the system of parallel isolated cylinders on the cyclic air flow, while taking into consideration the dust sediment accumulation;

- to calculate the breathing resistance of respirators to determine their period of protective action when modelling various modes of load on the worker;

- to test experimentally the correspondence of the obtained dependence of the change in the pressure drop on the filter half mask during the oscillatory movement of the air flow.

\section{Materials and Methods}

The study presented continues the cycle of theoretical works [22-25], which deal with modelling the process of viscous cyclic air flowing around the system of parallel isolated cylinders (Figure 1), placed perpendicularly to the direction of air flow, which is, in some approximation, a respirator filter model.

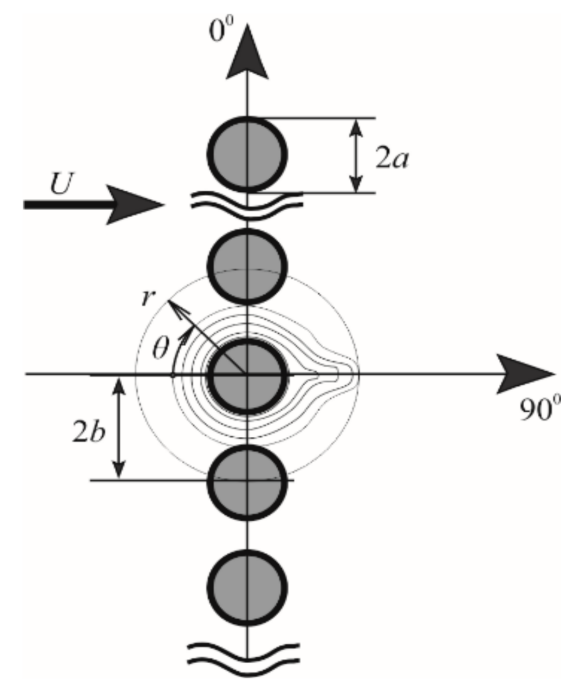

Figure 1. Schematic diagram of a separate row of arranging parallel fibres (calculation section): $\mathrm{a}$-fibre radius, $\mathrm{m}$; $\mathrm{b}$-distance between the axes of the adjacent cylinders, $\mathrm{m} ; r, \theta$ - polar coordinates; $U$-air velocity $\mathrm{m} / \mathrm{s}$.

Within the given system, which is proposed by S. Kuwabara [26], each cylinder which presents a filter fibre is encircled by an imaginary coaxial cylindrical surface, at the boundary of which it is assumed that the radial velocity component is equal to the velocity of the undisturbed flow. Inside the porous shell, the flow field is described by the Brinkman equation (modified Darcy's equation) [27] along with the flow continuity equation. Furthermore, the flow field for the system of isolated cylinders does not depend on the Reynolds number [28], according to Stokes, but is determined by the ratio of the cylinder diameter and the size of coaxial cylindrical surface which encircles the cylinder. As the basis of the calculations, the flow field found by S. Kuwabara is taken, which is expressed by the dimensionless function of the flow ( $\Psi)$ [26] near the cylinder:

$$
\psi(r, \theta)=\left[\left(\frac{a}{r}\right)^{-1}-\frac{r}{b}+\frac{2 \cdot r}{a} \cdot \ln \frac{b}{a}\right] \cdot \frac{a \cdot \cos (\theta)}{2 \cdot r \cdot(-0,5 \cdot \ln \beta-\lambda)},
$$


where $r, \theta$ are polar coordinates; $a$ is the fibre radius, $\mathrm{m} ; b$ is the distance between the axes of adjacent cylinders, $\mathrm{m} ; \lambda$ is the dimensionless factor, which depends on the spacing of adjacent fibres; $\beta$ is the packing density of the filter fibres:

$$
\beta=\frac{G}{\rho \cdot H^{\prime}}
$$

where $G$ is the surface density of the filter fibre packing, $\mathrm{g} / \mathrm{m}^{2} ; \rho$ is the mass of the material of the filter, $\mathrm{g} / \mathrm{m}^{3} ; \mathrm{H}$ is the thickness of the filtering layer, $\mathrm{m}$.

On the surface of the cylinder itself, for viscous flow, there is a condition when radial and tangential velocities are equal to zero. The resistance force of the cylinder with such porous surface is defined by the integral of the composite stress over the external shell surface. In this case, the pressure drop in the filter equals [19]:

$$
\Delta p=\mu \cdot R_{0} \cdot L^{-1} \cdot U,
$$

where $\mu$ is the dynamic viscosity of the air, Pa.s; $R_{0}$ is the non-dimensional force of resistance of the fibre to the air flow; $L$ is the length of fibres in the filter, $\mathrm{m}$; $U$ is airflow velocity, $\mathrm{m} / \mathrm{s}$.

To calculate the non-dimensional force of a fibre, there is a variety of formulas available [29-32], which are modifications of expressions obtained in the Ozeenian approximation by Langmuir when solving the Navier-Stokes equations. The most widespread expression was obtained by M.O. Fuks and I.B. Stechkina [33].

$$
R_{0}=\frac{4 \cdot \beta}{-1.115 \cdot \ln \beta-\lambda} .
$$

The results of theoretical calculations by this formula were confirmed by experimental tests [34-38].

Let us consider the process of viscous cyclic air flowing around the system of parallel isolated cylinders, which fluctuates according to the harmonic law, which is submitted in a complex form $U=U_{0} \cdot e^{-i \omega t}$, where $U_{0}$ is the initial velocity of the undisturbed air flow, $\mathrm{m} / \mathrm{s} ; \omega$ is pulsation frequency, $1 / \mathrm{s} ; t$ is time, $\mathrm{s}$. We assume that at the starting moment, velocity distribution is symmetric in relation to a certain plane which passes through the axis of the cylinder, while at infinity, the flow levels out in parallel motion (or direction). The total resistance to the air flow of the model is equal to the sum of the resistances of all cylinders (fibres), and then the resistance force, which is proportional to the speed, in the complex form, is written as follows:

$$
R_{0}=\gamma_{k} \cdot U,
$$

where $\gamma_{k}=\gamma_{1}+i \gamma_{2}$ is the complex constant, (s/m), $i$ is an imaginary unit.

This expression can also be written as a sum of two components which are proportional, respectively, to the velocity $U(\mathrm{~m} / \mathrm{s})$ and acceleration $\dot{U}\left(\mathrm{~m} / \mathrm{s}^{2}\right)$ [39].

$$
R_{0}=\left(\gamma_{1}+i \cdot \gamma_{2}\right) \cdot U=\gamma_{1} \cdot U+\frac{\gamma_{2}}{\omega} \cdot \dot{U},
$$

Having determined the acceleration as a derivative of the air velocity and rejecting the imaginary part, we obtain:

$$
R_{0}=U_{0} \cdot\left(\gamma_{1} \cos (\omega t)-\gamma_{2} \sin (\omega t)\right),
$$

Thus, the first part of the expression, which is related to the real part of the variable $\gamma$, is proportional to the velocity and corresponds to the resistance force of friction on the cylinder surface. The other part can be called inertial; it depends on the frequency of respiratory movements. 
Variable $\gamma_{1}$ depends on the density of fibres, which can be presented based on solving equations of stream function near the surface of an isolated cylinder, taking into account the influence of adjacent fibres by formula [39] $\gamma_{1}=(a \cdot 4 \cdot \pi) /(v \cdot(-0.5 \cdot \ln \beta-\lambda))$, where $v$ is the kinematic viscosity of the air, $\left(\mathrm{m}^{2} / \mathrm{s}\right)$. Variable $\gamma_{2}$, according to the assumption of Landau [40], is found by the formula: $\gamma_{2}=\sqrt{2 \cdot \rho_{p} / \omega \cdot \mu} \cdot(i-1)$, where $\rho_{\text {п }}$ is the air flow density, $\left(\mathrm{kg} / \mathrm{m}^{3}\right)$. If we omit the imaginary part, the formula for calculating the value of non-dimensional resistance force of the filter fibres is written as follows:

$$
R_{0}=U_{0} \cdot\left[\frac{4 \cdot a \cdot \pi \cdot v^{-1} \cdot \cos (\omega t)}{-0.5 \cdot \ln \beta-\lambda}+\sqrt{\frac{2 \cdot \rho_{p}}{\omega \cdot \mu}} \cdot \sin (\omega t)\right],
$$

Meanwhile, the expression for estimating pressure drop $(\Delta p, \mathrm{~Pa})$ is written as:

$$
\Delta p=\mu \cdot L^{-1} \cdot U_{0}^{2} \cdot\left[\frac{4 \cdot a \cdot \pi \cdot v^{-1} \cdot \cos (\omega t)}{-0.5 \cdot \ln \beta-\lambda}+\sqrt{\frac{2 \cdot \rho_{p}}{\omega \cdot \mu}} \cdot \sin (\omega t)\right],
$$

As can be seen from formula (10), the increase in respiratory rate results in an increase in the amplitude of fluctuations in pressure drop.

To determine a change in the pressure drop during the dust sediment accumulation on respirator filters, we use Krish's assumption that fibres with an asymmetric sediment can be approximated by a circular cylinder with a cross-sectional area equal to the midsection area of the dust-laden fibre (thickened fibre model) [41,42]. It is considered that the length of the fibres per unit volume does not change, and the increase in the pressure drop is conditioned by the thickening of the sediment layer on the dusty fibres. This model, in contrast to the dendritic one [43,44], allows consideration of the influence of the accumulated dust sediment on the hydrodynamics of the air flow movement. The pressure drop is determined by the formula [45]:

$$
\Delta p(t)=\mu \cdot L^{-1} \cdot U_{0} \int_{0}^{H} R_{0}\left[a_{n}(x, t)\right] d x,
$$

where $R_{0}\left(a_{n}(x, t)\right)$-dimensionless force acting per unit length of dust-laden fibre with radius $a_{n}(x, t)$, which is located at the depth of the filter $\mathrm{x}$ during the time $\mathrm{t}$ from the beginning of dust accumulation.

To calculate the change in the fibre radius during the accumulation of dust sediment, we use the formula proposed by Dunnett and Clement [34]:

$$
a_{n}=a\left[1+h\left(1-k \xi^{b}\right)\right]
$$

where $h$ is the ratio of the height of the dust sediment on the filter fibre to its radius; $k, b$ are empirical coefficients depending on the physical-chemical properties of dust, air humidity, and particle shape; $\xi$ is the angle formed by the dust sediment on the fibre. The values of the empirical coefficients are specified in the course of experimental research. Some data on their values can be found in a previous work [46].

The growth of the fibre radius depends on the number of settled particles, which can be represented as:

$$
N(x, t)=\frac{\pi \beta_{2}\left(a_{n}-a\right)}{V_{p} L}=\frac{\pi M}{V_{p} L}
$$

where $\beta_{2}$ is density of sediment on the surface of the filter fibre, $\mathrm{kg} / \mathrm{m}^{3} ; M=\beta_{2} h_{1}$ is dust holding capacity, $\mathrm{kg} / \mathrm{m}^{2} ; h_{1}$ is dust sediment height, $\mathrm{m} ; V_{p}$ is dust particle volume, $\mathrm{m}^{3}$

The process of settling the aerosol particles on a cylinder can be expressed by the well-known equation:

$$
\left\{\begin{array}{l}
\frac{\partial N_{0}}{\partial x}=-\gamma(x, t) N_{0} \\
\frac{\partial N}{\partial t}=U_{0} \gamma(x, t) N_{0}
\end{array},\right.
$$


where $N(x, t)$ is number of settled particles over time $t$ per unit volume of the filter at depth $x ; \gamma(x, t)$ is filtration coefficient, which is determined by the formula:

$$
\gamma=\frac{2 \eta(a) \beta H}{\pi a^{2}},
$$

where $\eta(a)$ is the total coefficient of capturing the aerosol particles by the filter fibres.

To introduce the dimensionless variables $m=M / M_{0}$ into the second equation of the system (14), where $M_{0}$ is the maximum dust holding capacity of the filter, when reaching the limiting pressure drop, $\mathrm{kg} / \mathrm{m}^{2} ; h=x / H, n=N / N_{0}, t^{\prime}=t L V_{p} U_{0}(t) \pi^{-1}$, then it can be written in a more general form:

$$
\frac{d m}{d t^{\prime}}=\frac{\eta\left(a_{n}\right) n\left(t^{\prime}\right)}{m} .
$$

From this equation, the time of the filtration phase end can be obtained:

$$
t^{\prime}=\int_{0}^{m_{1}} \frac{m d m}{\eta\left(a_{n}\right)}
$$

where $m_{1}=m(0, t)$ is dimensionless dust holding capacity on the fibre surface, formed by a layer of aerosol particles, the thickness of which overlaps the distance between the fibres.

Having determined $n\left(t^{\prime}\right)$ from Equation (15) and substituting it into the first equation of the system (14) after appropriate transformations, it is possible to obtain:

$$
\frac{\partial}{\partial h}\left(\frac{m}{\eta\left(a_{n}\right)} \frac{d m}{d t^{\prime}}\right)+\frac{N_{0} a^{2}}{\beta} \frac{\partial}{\partial t^{\prime}}=0,
$$

with initial conditions $m(h, 0)=1, m\left(0, t^{\prime}\right)=m 1, c\left(0, t^{\prime}\right)=1$.

Expression (17), taking into account the independence of the mixed derivative from the differentiation order, makes it possible to obtain an equation for calculating the amount of settled dust on the fibres, which changes with the dust sediment accumulation:

$$
\frac{d m}{d h}+\frac{\eta\left(a_{n}\right) m}{m} \frac{N_{0} a^{2}}{\beta}=0 .
$$

Thus, using expression (18) to replace the integration variable by $m$ in (11), we obtain the formula for calculating the pressure drop during dust accumulation:

$$
\Delta p(t)=\mu \cdot L^{-1} \cdot U_{0} \cdot \int_{0}^{m_{2}} \frac{R_{0}\left(a_{n}\right) m d m}{\eta\left(a_{n}\right)} .
$$

where $m_{2}=m\left(h_{1}, t\right)$ is dimensionless dust holding capacity on the fibre surface at the final moment with thickness $h_{1}$.

To verify the compliance of formulas (10) and (20), theoretical calculations have been compared with experimental data of determining the pressure drop on disposable filter respirators of the Standart brand with a surface area $S=0.005 \mathrm{~m}^{2}$, manufactured commercially by SPE "Standart" (Dnipro, Ukraine) from "Elephlen" material, taking into consideration the dust sediment accumulation on the filter fibres. The parameters of the filtering polypropylene material are given in Table 1.

Table 1. Parameters of the filtering polypropylene material Elephlen.

\begin{tabular}{ccccc}
\hline $\begin{array}{c}\text { The Average Radius of } \\
\text { the Fibres, } \\
\boldsymbol{a}, \boldsymbol{\mu \mathrm { m }}\end{array}$ & $\begin{array}{c}\text { Surface Density } \\
\text { of Fibre Packing, } \\
\boldsymbol{G} ; \mathbf{g} / \mathbf{m}^{\mathbf{2}}\end{array}$ & $\begin{array}{c}\text { Filtering Layer } \\
\text { Thickness, } \\
\boldsymbol{H}, \mathbf{m m}\end{array}$ & $\begin{array}{c}\text { Coefficient, } \\
\lambda\end{array}$ & $\begin{array}{c}\text { Fibre Length } \mathbf{~}^{\mathbf{m}} \\
\boldsymbol{L}, \mathbf{m}\end{array}$ \\
\hline 2.5 & 45 & 3.2 & $0.8-1.3$ & $7.96 \cdot 10^{-6}$ \\
\hline
\end{tabular}

${ }^{1}$ Note. The total length of the fibres is defined in $1 \mathrm{~m}^{2}$. 
Experimental evaluation of the pressure drop on the filter respirators was performed in accordance with the requirements of EN 149:2001 + A1:2009. For this purpose, a special breathing machine was used (Figure 2), which consisted of a Sheffield dummy head with integrated concentric breathing tubes (Figure 3), and a piston cylinder with a working volume of $2.5 \mathrm{~m}^{3}$, which was connected to an AIRE56V2 electric motor through a device for converting rotational motion into reciprocating. The number of revolutions on the shaft was controlled by a HYUNDAI N700E-004HF frequency converter.

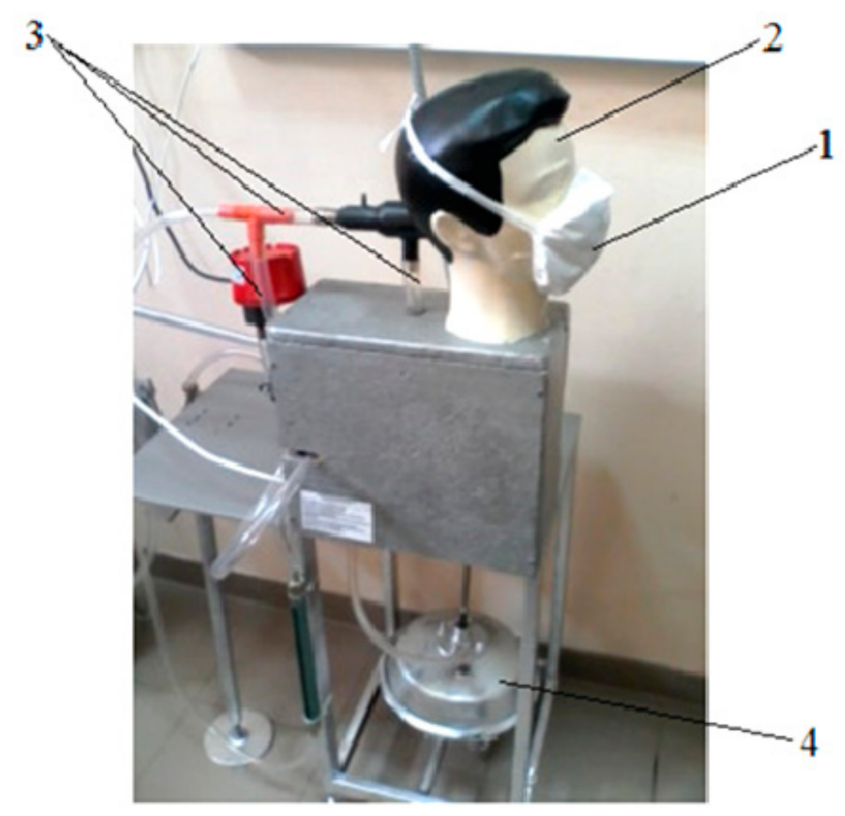

Figure 2. External view of the installation for determining the pressure drop in the filter respirator: 1-air supply to the respirator; 2-dummy heads; 3-air ducts; 4-breathing machine.
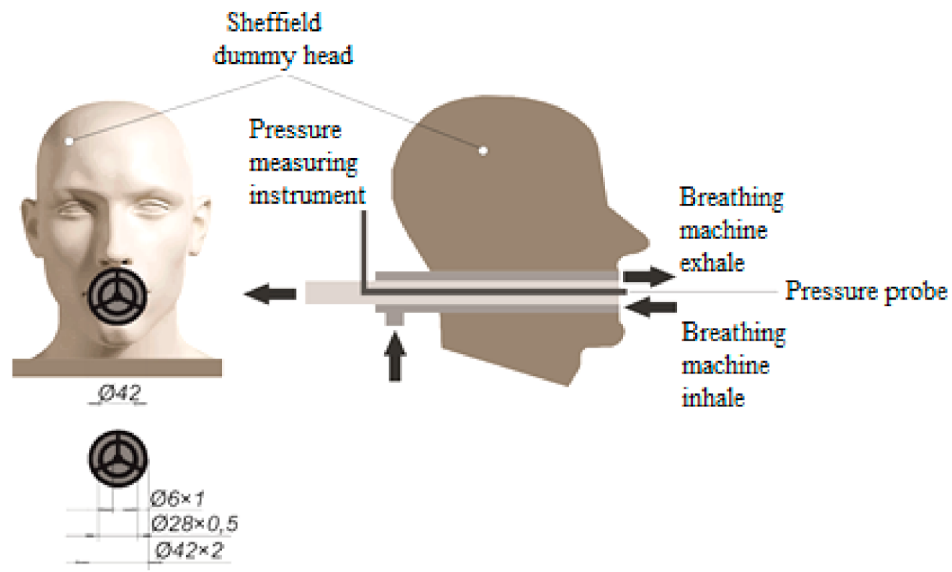

Figure 3. Sheffield dummy head.

The process of exhalation passed through the outer tube, and that of inhalation passed through the inner one. To regulate the air flow, solenoid valves were used. For the research, the filter half mask (respirator) was tightly placed on the dummy head. Then, the electric motor was turned on and, using a frequency converter, the number of breaths and the volume of transported air were set in accordance with the depth of breathing, which corresponds to the work mode (Table 2). The amount of air supplied to the respirator was measured using an RM 0.025ZhUZ flow meter. 
Table 2. Parameters of the filtering material Elephlen.

\begin{tabular}{cccc}
\hline $\begin{array}{c}\text { Indicators Characterizing the } \\
\text { Process of a User's Breathing }\end{array}$ & Easy Work & $\begin{array}{c}\text { Medium Physical } \\
\text { Activities }\end{array}$ & Hard Work \\
\hline Respiratory rate, cycle per minute & 21.9 & 26.5 & 31.9 \\
Depth of breathing, l & 1.45 & 1.86 & 2.3 \\
Average air flow rate, 1/min & 31.3 & 49.4 & 73.3 \\
Filtering rate, $\mathrm{m} / \mathrm{s}$ & 0.105 & 0.165 & 0.24 \\
\hline
\end{tabular}

The pressure drop was measured by means of a probe as specified in EN 149:2001 + A1:2009 standard, using an electronic differential pressure gauge "Testo 512" with a measuring range of $0-2$ mbar. Ten samples were used for the study.

To model a change in the pressure drop in the respirators during dust sediment accumulation, they were placed in a special dust chamber (Figure 4).

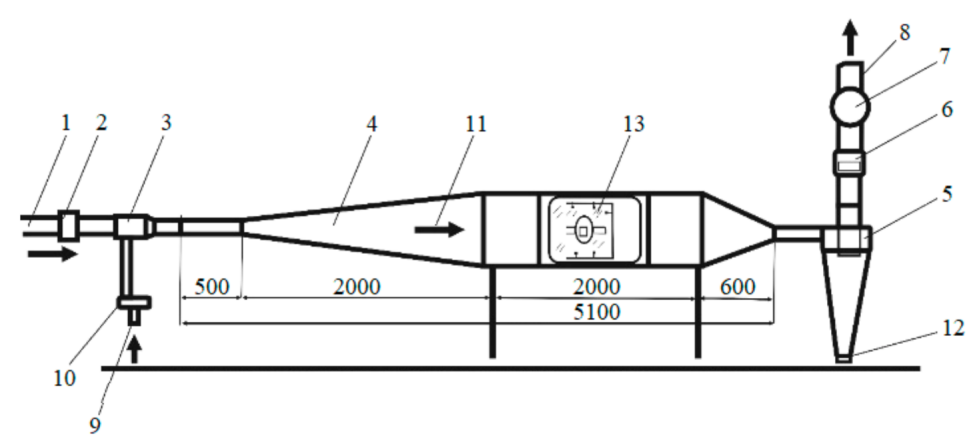

(a)

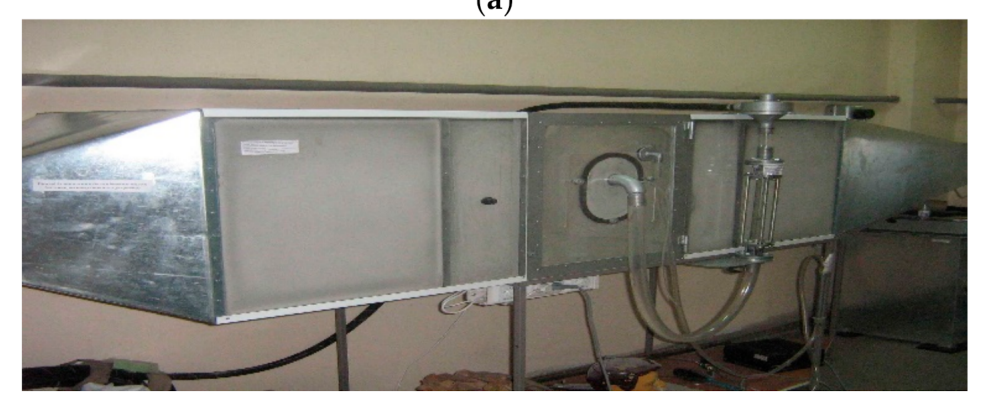

(b)

Figure 4. Test stand: (a) schematic view; (b) general view; 1, 9: compressed air supply; 2: pre- filter for compressed air treatment; 3: ejector; 4: diffuser; 5: cyclone; 6: flowmeter; 7: exhaust fan; 8: outlet pipe; 10: dust generator; 11: dust distributor; 12: damper; 13: test chamber.

The cross-sectional area of the test chamber is $42 \mathrm{~m}^{2}$, as required by the procedure according to the requirements of EN 13274-8:2005, "Personal respiratory protection equipment. Test methods. Part 8 . Detection of plugging with dolomite dust". The concentration of dolomite dust was provided equal to $1000 \pm 50 \mathrm{mg} / \mathrm{m}^{3}$. The time of dust contamination was determined by the achievement of the finite pressure difference in the half masks.

Using the ejector (3) and compressor Forte FL-24 (1) at an air flow rate of $60 \mathrm{~m}^{3} / \mathrm{h}$, the dolomite dust DRB 4/15 was fed from the dust generator Palas RBG 1000 (particle size range of $0.1 \mathrm{um}-0 \mathrm{um}$, mass flow range of $10 \mathrm{mg} / \mathrm{h}-500 \mathrm{~g} / \mathrm{h}$ ) 10 through the diffuser (4) and dust distributor (11) to the test chamber (13). The diffuser and distributor in the test stand design ensure uniform distribution of dust and air flow over the chamber height. The air flow in the chamber is controlled by the flowmeter RM 0.025ZhUZ 3.6. To remove dust from the chamber and protect the environment, the exhaust fan VENTS VCUN $250 \mathrm{x}$ 127-2.2-4 (7) with a cyclone COL-1.5 (5) was installed.

The half mask of the dust respirator was installed on a dummy head and placed in the test chamber. The dummy head had a special tube mounted onto it through which the 
connection with the breathing machine was ensured, and there was a micromanometer connected to monitor changes in the pressure drop. Temperature and humidity control was ensured via "TXA" sensors.

To determine the dust concentration, a constant volume of air at the flow rate of $2 \mathrm{dm}^{3} /$ min was drawn through the "AFA VP-10" filter using an aspirator. The prolong for fixing the "AFA VP-10" filter was placed in the middle of the chamber near the test sample. The concentration of dust in the chamber was determined using the formula:

$$
C=\frac{10^{3} \cdot\left(m_{2}-m_{1}\right)}{Q \cdot t}
$$

where $m_{1}$ is weight of the "AFA VP-10", $\mathrm{mg} ; m_{2}$ is weight of the "AFA VP-10" filter with dust after sampling, $\mathrm{mg}$; $Q$ is air flow, $\mathrm{dm}^{3} / \mathrm{min}$.; $t$ is time of air sampling, $\min$.

The initial mass of "AFA VP-10" filters having a diameter of $36 \mathrm{~mm}$ before and after the study with sedentary dust was checked on "VLO 200" laboratory scales. Time was controlled by an "HS 43" electronic stopwatch.

The results of the experimental data were averaged with the estimation of the measurement uncertainty at $\mathrm{P}<0.05$ according to the Evaluation of measurement data-Guide to the expression of uncertainty in measurement-JCGM 100:2008.

The rate of filtration through the filter surface of the respirator was calculated based on the modes of physical activities: light, average, and heavy ones by the formula $U=$ $Q / S$, where $Q$ is the volume of the air which is breathed in and out by a person $\mathrm{m}^{3} / \mathrm{s}$. Taking into account the known data on the characteristics of the respiratory process during different types of exercise $[47,48]$, we calculated the filtration rate (Table 2).

\section{Results}

The experimental data obtained on the value of the pressure drop on the filter respirator when simulating the process of breathing, corresponding to works of different difficulty, is shown in Figure 1 in the form of points. The nature of its change corresponds to the indicators published in previous works $[49,50]$, which show the results of studies on the effect of RPE respiratory resistance on their protective properties and human physiology.

The curves which characterize pressure drop change in a filter respirator based on the given input data are calculated by formula (10) using a software product to perform various mathematical and technical calculations-"Matlab" - are given in Figure 5.

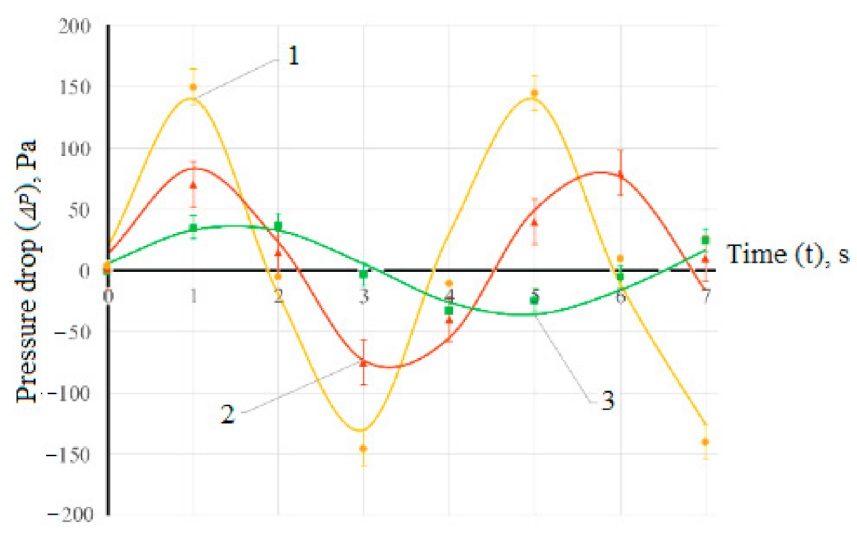

Figure 5. Dependence of the pressure drop $(\Delta p)$ in the dust respirator on time $(t)$ when performing easy work (1), medium physical activity (2) and hard work (3).

The results of theoretical calculations compared with experimental data on the change in the pressure drop on the respirator with dust sediment accumulation according to formula (19) are given in Figure 6. The period of protective action of filters can be determined by the time of the bulk phase end of the dust particle accumulation - that is, when the pores between the fibres are plugged and the process of dust sediment formation on the 
filter surface begins [25]. Theoretically, this time can be determined by formula (16). In practice, in the course of the experiment on dusting the filters, it is determined with the beginning of a sharp increase in the resistance to air flow (Figure 7).

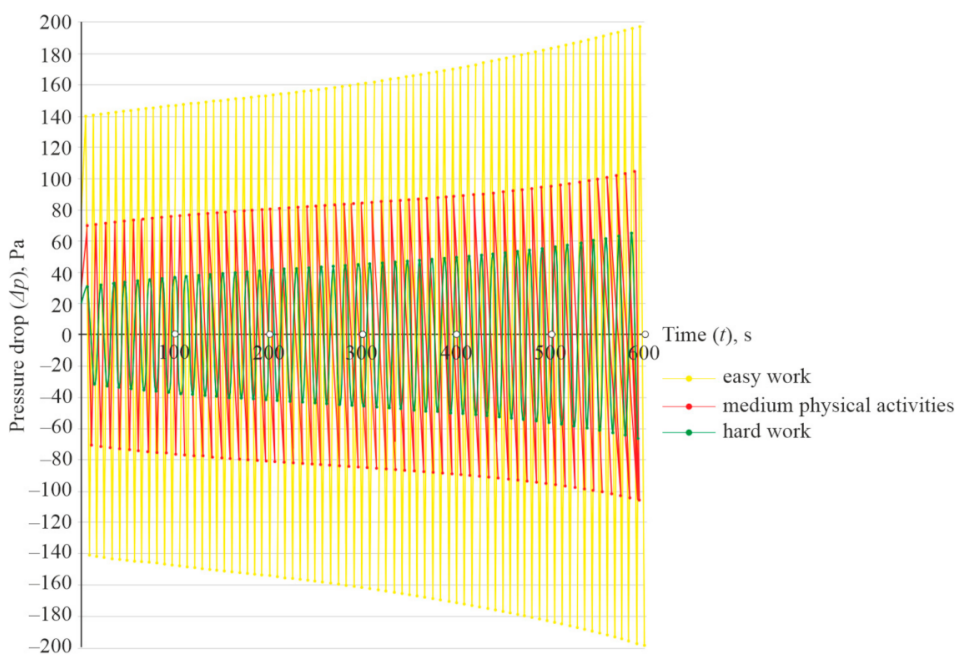

Figure 6. Graph of change in the pressure drop $(\Delta p)$ of respirator filters over time $(t)$ at a pulsating flow with a volumetric flow rate of $2.5 \mathrm{dm}^{3}$ per stroke; frequency of oscillating movements $21 \mathrm{~min}^{-1}$; when dusting with dolomite dust with a concentration of $1000 \mathrm{mg} / \mathrm{m}^{3}$.

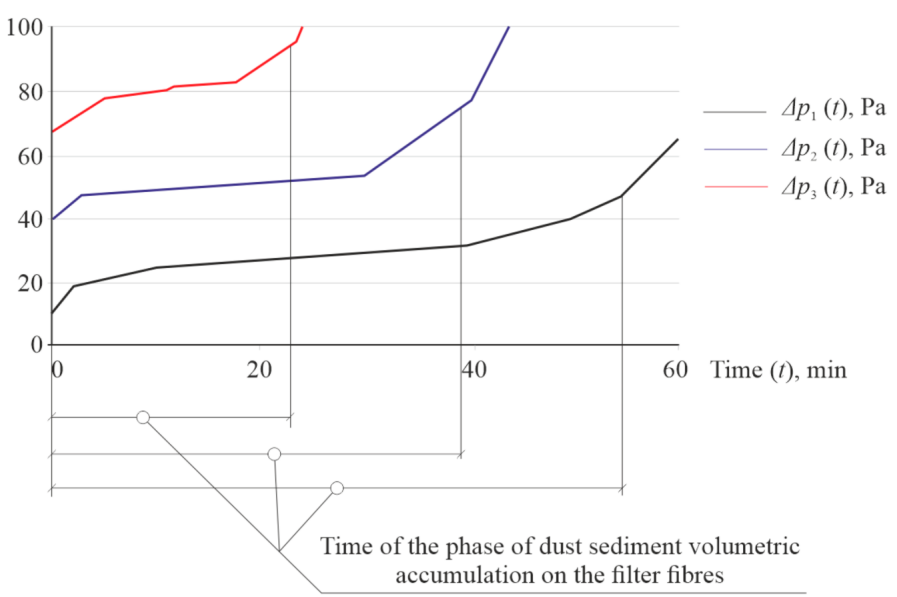

Figure 7. Curves of change in the pressure drop of the respirator with the accumulation of dust sediment with a concentration in the dust chamber of $500 \mathrm{mg} / \mathrm{m}^{3}$ at a constant air flow: $1-30 \mathrm{dm}^{3} / \mathrm{min}$; $2-85 \mathrm{dm}^{3} / \mathrm{min} ; 3-120 \mathrm{dm}^{3} / \mathrm{min}$.

Of course, the filter can be used further, but there is a certain physiological limitation of the pressure drop value, above which it will be rather difficult for a person to breathe and perform production operations. Several works are devoted to the determination of this limit threshold [51-55]. Additionally, one of the results of the research performed is the increase in the weight of the settled dust on the filter fibres before the critical pressure drop occurs (Table 3). 
Table 3. Dust holding capacity of "Standart" respirators at various work modes with a dolomite dust concentration of $1000 \mathrm{mg} / \mathrm{m}^{3}$ in the test chamber.

\begin{tabular}{|c|c|c|c|}
\hline Work Mode & $\begin{array}{l}\text { Time of Dusting (min) } \\
\text { before the Beginning } \\
\text { of the Surface } \\
\text { Accumulation Phase }\end{array}$ & $\begin{array}{l}\text { Amount of Dust } \\
\text { Settled on the } \\
\text { Respirator Fibres, } g\end{array}$ & $\begin{array}{l}\text { Dust Holding } \\
\text { Capacity, } \\
\text { kg/m } / \mathbf{m}^{2}\end{array}$ \\
\hline Easy work & 24 & 3.6 & 0.72 \\
\hline Medium physical activity & 16 & 2.2 & 0.44 \\
\hline Hard work & 9 & 1.3 & 0.26 \\
\hline
\end{tabular}

The value of the dust holding capacity makes it possible to set the period of protective action using formula (17) at various dust concentrations and work modes, as shown in Table 4.

Table 4. Period of protective action of "Standart" respirators at various dolomite dust concentrations in the air.

\begin{tabular}{cccc}
\hline Work Mode & $\begin{array}{r}\text { Period of Protective Action of “Standart" Respirators (min) at } \\
\text { Dolomite Dust Concentration in the Air, } \mathbf{~} \mathbf{m} / \mathbf{m}^{\mathbf{3}}\end{array}$ \\
\hline Easy work & 24 & 3.6 & 0.72 \\
Medium physical activity & 16 & 2.2 & 0.44 \\
Hard work & 9 & 1.3 & 0.26 \\
\hline
\end{tabular}

\section{Discussion}

The analysis of the obtained results allows us to conclude that the proposed model of the flow of viscous cyclic air around the system of parallel isolated cylinders allows us to determine the change in pressure drop in the filters, based on the different breathing modes of workers, which are characteristic of certain physical activities during production function performance. The graphs show the change in the amplitude of the obtained curves, which characterizes the depth, the number of cycles of breathing and respiratory movements when physical activities increase, which is characteristic of the real process of the breathing of the worker when performing production functions.

It should be noted that formula (10) takes into account the decreasing value in the disk on the filter caused by increasing its area due to changes in the initial filtration rate, which is determined based on air flow according to the physical load of the worker when performing production functions [56]. One can see good quantitative and qualitative agreement between the experimental data and the theoretical curves, which shows the fact that the model equation is suitable for calculating the pressure drop on the respirator during breathing, while the index of dissimilarity according to Student's test showed a discrepancy of up to $20 \%$. Similar experimental sinusoids, which characterize a change in the pressure drop on respirators, are used by Clothilde Brochot in studies to determine their protective factor, taking into account the permeability of aerosol through the sealing strip of the half mask [57].

At the same time, with the additional resistance of breathing connected to the person, the duration of the inhalation and exhalation phases [58] increases. Moreover, the exhalation phase can be up to 1.5 times longer than the inhalation phase $[59,60]$.

Unfortunately, this model does not indicate the difference between the respiratory phases. This requires further study on the laws that characterize the movement of air through the respirator filter, taking into account the peculiarities of the user's respiratory muscles. However, according to the data established, it is possible to estimate the rate of fatigue of workers, when the breathing process is significantly hampered, which is characterized by an increase in the depth (amplitude) of respiration [61].

The value of the pressure drop is decisive when both calculating the period of protective action and assessing the protective efficiency of the respirator. Thus, due to the presence of peak values, which are characteristic of the oscillating air motion, the filtration 
rate will also change [62]. This can lead to an increase in the uneven distribution of air load over the area of the filter and the appearance of sections in which the penetration rate will increase sharply. The latter is decisive for the period of protective action, which can be estimated by the known formulas [63] for dust filters:

$$
t_{k}=\frac{2.3 a}{U_{0} \cdot K_{p e n}} \lg \left(1-2^{-1 / k}\right)^{-1},
$$

where $k$ is the coefficient of fouling of the filtering layer, which depends on the concentration of dust in the working area, the size of aerosol particles, the coefficient of capturing the aerosol particles by the filter (0.6); $K_{\text {pen }}$ is the coefficient of penetration of aerosol through the filter, $K_{p e n}=10^{-\gamma\left(\Delta p \cdot U^{-1}\right)} ; \alpha$ is the filtration coefficient, which is calculated based on the mechanisms of capturing the aerosol particles by a system of parallel isolated cylinders.

When comparing the obtained results of the protective action period with the results calculated by the known formula (22) (Table 5), some discrepancies were revealed.

Table 5. Comparison of the protective action period of "Standart" respirators, calculated at a dust concentration of $50 \mathrm{mg} / \mathrm{m}^{3}$.

\begin{tabular}{ccc}
\hline \multirow{2}{*}{ Work Mode } & \multicolumn{2}{c}{ Period of Protective Action (min), Calculated by } \\
\cline { 2 - 3 } & Formula (17) & Formula (22) \\
\hline Easy work & 725 & 835 \\
Medium physical activity & 362 & 426 \\
Hard work & 154 & 304 \\
\hline
\end{tabular}

This is conditioned by the presence of peak jumps in the pressure drop during oscillatory movement, while in formula (22), the average value of the pressure drop is used for calculations. Thus, the accumulation of dust deposits also results in an increase in air resistance and, accordingly, affects the lifetime of such a filter, particularly due to the appearance of peak resistance of filters to air flow.

\section{Conclusions}

The theoretical dependence of the pressure drop in respirator filters is proposed for the first time, which is represented by a system of parallel isolated cylinders, whose length corresponds to the total length of filter fibres, the air flow field near which is described by the Brinkman equation in combination with the equation of continuity of flow and fluctuates according to the harmonic law, which allows the prediction of the physical load on workers when performing production functions, assessing the impact of additional air flow resistance from increasing physical activities on the worker and determining the effective service life of the filter.

The dependence has been verified of the pressure drop on the filters with the accumulation of the dust pressure during the oscillatory air flow movement. It was possible to calculate the period of protective action of filters, which is limited by a certain value of breathing resistance and determined by the time at which the volumetric filtration phase ends.

Author Contributions: Conceptualization, O.B.; methodology, A.E.; software, S.C. and V.L.; validation, S.C. and O.D.; formal analysis, Y.C. and P.S.; investigation, A.E. and S.C.; resources, O.D.; data curation, Y.C.; writing — original draft preparation, A.E. and S.C.; writing—review and editing, P.S. and V.L.; visualization, P.S. and I.K.; supervision, O.B.; project administration, O.B.; funding acquisition, O.B. All authors have read and agreed to the published version of the manuscript.

Funding: This study was carried out as part of the project "Belt and Road Initiative Centre for ChineseEuropean Studies" and was funded by the Guangdong University of Petrochemical Technology.

Institutional Review Board Statement: Not applicable. 
Informed Consent Statement: Not applicable.

Data Availability Statement: Data are contained within the article.

Acknowledgments: The team of authors express their gratitude to the reviewers for valuable recommendations that have been taken into account to improve significantly the quality of this paper. We gratefully acknowledge Maksym Vasylchenko for the opportunity to conduct experimental research presented in the article in the laboratory, which meets the requirements of ISO17025.

Conflicts of Interest: The authors declare no conflict of interest.

\section{References}

1. Ramirez, J.; O'Shaughnessy, P. Filter penetration and breathing resistance evaluation of respirators and dust masks. J. Occup. Env. Hyg. 2016, 14, 148-157. [CrossRef] [PubMed]

2. Kadam, V.; Kyratzis, I.L.; Truong, Y.B.; Schutz, J.; Wang, L.; Padhye, R. Electrospun bilayer nanomembrane with hierarchical placement of bead-on-string and fibers for low resistance respiratory air filtration. Sep. Purif. Technol. 2019, 224, 247-254. [CrossRef]

3. Li, Y.; Yin, X.; Si, Y.; Yu, J.; Ding, B. All-polymer hybrid electret fibers for high-efficiency and low-resistance filter media. Chem. Eng. J. 2020, 398. [CrossRef] [PubMed]

4. Johnson, A.T. Respirator masks protect health but impact performance: A review. J. Biol. Eng. 2016, 10, 1-12. [CrossRef]

5. Tan, Y. Toward a law of healthy peoples: From the Perspective of the Right to Health. Future Hum. Image 2020, 13. [CrossRef]

6. Banerjee, R.; Roy, P.; Das, S.; Paul, M.K. A hybrid model integrating warm heat and ultraviolet germicidal irradiation might efficiently disinfect respirators and personal protective equipment. Am. J. Infect. Control 2021, 49, 309-318. [CrossRef]

7. Sapbamrer, R.; Hongsibsong, S.; Naksata, M.; Naksata, W. Insecticide Filtration Efficiency of Respiratory Protective Equipment Commonly Worn by Farmers in Thailand. Int. J. Env. Res. Public Health 2021, 18, 2624. [CrossRef]

8. Johnson, A.T.; Scott, W.H.; Lausted, C.G.; Benjamin, M.B.; Coyne, K.M.; Sahota, M.S.; Johnson, M.M. Effect of Respirator Inspiratory Resistance Level on Constant Load Treadmill Work Performance. Am. Ind. Hyg. Assoc. J. 1999, 60, 474-479. [CrossRef]

9. Nosal, D.; Konovalov, S.; Shevchenko, V. Determination of the injury probability among coal mine workers. Min. Min. Depos. 2021, 15. accepted paper.

10. Bémer, D.; Calle, S. Evolution of the Efficiency and Pressure Drop of a Filter Media with Loading. Aerosol Sci. Technol. 2000, 33, 427-439. [CrossRef]

11. Balanay, J.A.G.; Lungu, C.T. Determination of pressure drop across activated carbon fiber respirator cartridges. J. Occup. Env. Hyg. 2016, 13, 141-147. [CrossRef]

12. Azarafza, A.; King, A.; Mead-Hunter, R.; Schuler, J.; Abishek, S.; Mullins, B. Prediction of Residual Saturation and Pressure Drop during Coalescence Filtration using Dynamic Pore Network Model. Sep. Purif. Technol. 2021, 254, 117588. [CrossRef]

13. Xia, T.; Chen, C. Evolution of pressure drop across electrospun nanofiber filters clogged by solid particles and its influence on indoor particulate air pollution control. J. Hazard. Mater. 2021, 402, 123479. [CrossRef]

14. Basmanov, P.I.; Kaminskiy, S.L.; Korobeinikov, A.V.; Trubitsyna, M.E. Respiratory Protective Devices. Reference Guide; GIPP "Iskusstvo Rossii": Saint Petersburg, Russia, 2020; ISBN 5-900-78671-4.

15. Beloglazov, I.N.; Golubev, V.O.; Tikhonov, O.N.; Mikheyev, A.I.; Beloglasov, I.I.; Vorobyov, S.A.; Palmer, J.; Kuukka, J.; Jaaskelainen, E.; Rogov, S.N. Filtration of Process Fine Materials; Ore and Metals: Moscow, Russia, 2008; ISBN 978-5-98191-035-7.

16. Voitovska, O.; Tolochko, S. Physical Education Teachers' Perspectives in a Changing World: From Future Studies to New Physical Culture. Philos. Cosmol. 2018, 20, 139-145. [CrossRef]

17. Nelson, T.J.; Jayjock, M.A.; Colton, C.E. How protective are respirator assigned protection factors: An uncertainty analysis. Aiha J. 2000, 61, 388-393. [CrossRef]

18. Laminger, T.; Stecher, M.; Mauschitz, G.; Höflinger, W. Modeling the pressure drop behavior of cleanable dust filters during pressure-controlled operation. Sep. Sci. Technol. 2017, 52, 2788-2794. [CrossRef]

19. Holinko, V.I.; Cheberiachko, S.I.; Radchuk, D.I.; Cheberiachko, Y.I. Study on aerodynamic breathing resistance of dust respi-rators. Nauk. Visnyk Natsionalnoho Hirnychoho Universytetu 2014, 6, 131-136.

20. Kolesnik, V.E.; Cheberiachko, S.I.; Cheberiachko, Y.I. Investigation of air resistance of dust respirators during their operation at mining enterprises. Metall. Min. Ind. 2014, 4, 118-123.

21. Holinko, V.; Cheberiachko, S.; Yavorska, O.; Radchuk, D. National Mining University Study of protective properties of half-masks respirators used by miners. Min. Min. Depos. 2016, 10, 29-36. [CrossRef]

22. Cheberiachko, S.; Cheberiachko, Y.; Sotskov, V.; Tytov, O. National Technical University Dnipro Polytechnic Analysis of the factors influencing the level of professional health and the biological age of miners during underground mining of coal seams. Min. Min. Depos. 2018, 12, 87-96. [CrossRef]

23. Feng, Z.; Long, Z.; Chen, Q. Assessment of various CFD models for predicting airflow and pressure drop through pleated filter system. Build. Env. 2014, 75, 132-141. [CrossRef]

24. Kirsh, V.A. Stokes flow past periodic rows of porous cylinders. Found. Chem. Eng. 2006, 40, 465-471. [CrossRef] 
25. Gupta, A.; Novick, V.J.; Biswas, P.; Monson, P.R. Effect of Humidity and Particle Hygroscopicity on the Mass Loading Capacity of High Efficiency Particulate Air (HEPA) Filters. Aerosol Sci. Technol. 1993, 19, 94-107. [CrossRef]

26. Kuwabara, S. The Forces experienced by Randomly Distributed Parallel Circular Cylinders or Spheres in a Viscous Flow at Small Reynolds Numbers. J. Phys. Soc. Jpn. 1959, 14, 527-532. [CrossRef]

27. Kirsch, A.A.; Stechkina, I.B. The theory of aerosol filtration with fibrous filters, Chapter 4. In Fundamentals of Aerosol Science; Shaw, D.T., Ed.; Wiley \& Sons., Inc.: New York, NY, USA, 1978; pp. 165-256.

28. Tamada, K.; Fujikawa, H. The steady two-dimensional flow of viscous fluid at low reynolds numbers passing through an infinite row of equal parallel circular cylinders. Q. J. Mech. Appl. Math. 1957, 10, 425-432. [CrossRef]

29. Kirsh, A.A.; Fuks, N.A. Studies on Fibrous Aerosol Filters: Resistance of parallel cylinder systems. Colloid J. 1967, $29,682-686$.

30. Kalinin, E.I.; Mazo, A.B. Steady and periodic regimes of laminar flow around the rotating cylinder. Tsagi Sci. J. 2011, 42, 637-653. [CrossRef]

31. Milne-Thomson, L.M. Theoretical Hydrodynamics, 5th ed.; Dover Publications Inc.: Mineola, NY, USA, 1998.

32. Kaminskiy, S.L. Fundamentals of Rational Respiratory Protection at Work; Prospekt Nauki: Saint Petersburg, Russia, 2007; ISBN 978-5-903090-09-9.

33. Stechkina, I.B.; Kirsh, V.A. Optimization of Parameters of Filters in a Multistage System of Fine Gas Filtration. Found. Chem. Eng. 2003, 37, 218-225. [CrossRef]

34. Dunnett, S.; Clement, C. A numerical study of the effects of loading from diffusive deposition on the efficiency of fibrous filters. J. Aerosol Sci. 2006, 37, 1116-1139. [CrossRef]

35. Sahimi, M.; Imdakm, A.O. Hydrodynamics of particulate motion in porous media. Phys. Rev. Lett. 1991, 66, 1169-1172. [CrossRef]

36. Kirsh, V.A.; Stechkina, I.B. Kinetics of the clogging and optimization of prefilters in a two-stage air cleaning system. Found. Chem. Eng. 2010, 44, 76-85. [CrossRef]

37. Leonov, A.N.; Kaptsevich, V.M.; Korneeva, V.K. Combined Filter Systems Based on Filters with Surface and Volumetric Filtration Mechanisms; BSATU: Minsk, Russia, 2017; ISBN 978-985-519-879-7.

38. Kirsh, V.A. The Deposition of Aerosol Submicron Particles on Ultrafine Fiber Filters. Colloid J. 2004, 66, 311-315. [CrossRef]

39. Happel, J.; Brenner, H. Low Reynolds Number Hydrodynamics; Springer: Berlin, Germany, 1981.

40. Landau, L.D.; Lifshits, E.M. Electrodynamics of Continuous Media; Nauka: Moscow, Russia, 1982; ISBN 978-5-02-014673-0.

41. Kirsh, A.A.; Burakov, A.E.; Tkachev, A.G.; Kirsh, V.A. Deposition of aerosol nanoparticles on filters coated with layer of carbon nanotubes. Colloid J. 2011, 73, 807-814. [CrossRef]

42. Kirsh, V.A.; Pripachkin, D.A.; Budyka, A.K. Inertial deposition of aerosol particles from laminar flows in fibrous filters. Colloid J. 2010, 72, 211-215. [CrossRef]

43. Hosseini, S.; Tafreshi, H.V. Modeling particle-loaded single fiber efficiency and fiber drag using ANSYS-Fluent CFD code. Comput. Fluids 2012, 66, 157-166. [CrossRef]

44. Wang, H.; Zhao, H.; Wang, K.; He, Y.; Zheng, C. Simulation of filtration process for multi-fiber filter using the Lattice-Boltzmann two-phase flow model. J. Aerosol Sci. 2013, 66, 164-178. [CrossRef]

45. Кирш, В.А. Модель запыленного фильтра с несимметричнымосадком частиц на волокнах. Коллоидный журнал 2014, 76, 472-476. [CrossRef]

46. Thomas, D.; Pacault, S.; Charvet, A.; Bardin-Monnier, N.; Appert-Collin, J.-C. Composite fibrous filters for nano-aerosol filtration: Pressure drop and efficiency model. Sep. Purif. Technol. 2019, 215, 557-564. [CrossRef]

47. Shevchenko, V.; Shevchenko, G.; Lebed, G. Recommended practice for using resource-saving technologies and tools for fine classification of uranium ores by size and refuse dehydration. Min. Min. Depos. 2016, 10, 69-76. [CrossRef]

48. Anderson, N.J.; Cassidy, P.E.; Janssen, L.L.; Dengel, D.R. Peak Inspiratory Flows of Adults Exercising at Light, Moderate and Heavy Work Loads. J. Int. Soc. Respir. Prot. 2006, 23, 53-63.

49. Clayton, M.P.; Bancroft, B.; Rajan, B. A Review of Assigned Protection Factors of Various Types and Classes of Respiratory Protective Equipment with Reference their Measured Breathing Resistances. Ann. Occup. Hyg. 2002, 46, 537-547. [PubMed]

50. Thompson, S.H.; Shahkey, B.J. Physiological Cost and Air Flow Resistance of Respiratory Protective Devices. Erg. 1966, 9, 495-499. [CrossRef]

51. Johnston, A.; Myers, W.; Colton, C.; Birkner, J.; Campbell, C. Review of Respirator Performance Testing in the Workplace: Issues And Concerns. Am. Ind. Hyg. Assoc. J. 1992, 53, 705-712. [CrossRef]

52. Caretti, D.M.; Scott, W.H.; Johnson, A.T.; Coyne, K.M.; Koh, F. Work Performance when Breathing Through Different Respirator Exhalation Resistances. Aiha J. 2001, 62, 411-415. [CrossRef]

53. Seo, H.; Kim, J.I.; Kim, H. Development of Korean Head forms for Respirator Performance Testing. Saf. Heal. Work. 2020, 11, 71-79. [CrossRef] [PubMed]

54. Cho, M.-H.; Kang, H.-W.; Shim, J.-E.; Lee, H.-G.; Seo, S. Evaluation of performance change by multiple use of a disposable respirator. J. Odor Indoor Env. 2020, 19, 66-73. [CrossRef]

55. Xu, M.; Lee, P.; Collins, D. The critical importance of mask seals on respirator performance: An analytical and simulation approach. PLoS ONE 2021, 16, e0246720. [CrossRef]

56. Lee, H.P. Effects of Long-Duration Wearing of N95 Respirator and Surgical Facemask: A Pilot Study. J. Lung Pulm. Respir. Res. 2014, 1, 97-100. [CrossRef] 
57. Brochot, C. Filtration of nanoparticles. In Application to Respiratory Protecting Devices. Choice and Use; Institute National Polytechnique de Lorraine: Vandœuvre-lès-Nancy, France, 2017; p. 180.

58. Silverman, L.; Lee, G.; Plotkin, T.; Sawyers, L.A.; Yancey, A.R. Air flow measurements on human subjects with and without respiratory resistance at several work rates. Arch. Ind. Hyg. Occup. Med. 1951, 3, 461-478.

59. Shevchenko, V.G. Research on the influence of miners' energy expenditure on coal mining efficiency. Nauk. Visnyk Natsionalnoho Hirnychoho Universytetu 2017, 3, 140-146.

60. Coyne, K.; Caretti, D.; Scott, W.; Johnson, A.; Koh, F. Inspiratory Flow Rates During Hard Work When Breathing Through Different Respirator Inhalation and Exhalation Resistances. J. Occup. Env. Hyg. 2006, 3, 490-500. [CrossRef]

61. Thomas, D.; Penicot, P.; Contal, P.; Leclerc, D.; Vendel, J. Clogging of fibrous filters by solid aerosol particles Experimental and modelling study. Chem. Eng. Sci. 2001, 56, 3549-3561. [CrossRef]

62. Kirsh, A.A.; Budyka, A.K. Filtration of aerosols with fiber materials FP. Russ. J. Gen. Chem. 2009, 79, 2045-2050. [CrossRef]

63. Radushkevich, L.V. Kinetics of formation and growth of aggregates on a solid obstacle from the flow of colloidal particles. Colloid J. 1964, 26, 194. 